\title{
Long-term settlement prediction at open dumping area using Hossein and Gabr method for new development
}

\begin{abstract}
In Malaysia, the most common method of disposal is landfill/open dumping. The soil at the dumping area are mixed with waste and soil. Thus, it was called as waste soil. Due to its heterogeneity properties, waste soil has a different settlement rate because different types of waste tends to settle differently. The Hussein and Gabr model which used empirical model was proposed to compute the long-term settlement. This Hussein and Gabr model is one of the soil settlement model that can be used to predict the long-term settlement at the dumping area. The model relates between the compression index and the time factor. The time factor are $\mathrm{t} 1, \mathrm{t} 2, \mathrm{t} 3$ and $\mathrm{t} 4$. The compression index is $\mathrm{CU} /=$ compression index and $\mathrm{C} 6 \mathrm{~b}$ is biodegradation index. The duration for initial compression, the compression, the biological compression and time creep are included in the model. The sample of waste soil is taken from closed dumping area in Lukut, Negeri Sembilan with the height of waste approximately 1 to 3 meters. The sample is tested using consolidation test for determining the geotechnical parameters and compressibility index. Based on the Hossein and Gabr model, the predicted long-term settlement for 20 years ( $q \mathrm{H}$ ) for the waste height of 1 to 3 meters are $0.21 \mathrm{~m}, 0.42 \mathrm{~m}$ and $0.63 \mathrm{~m}$ respectively and are below the percentages of proposed maximum settlement for waste soil which is acceptable for new development to takes place.. The types of deep or shallow foundation are proposed based on the predicted settlement. The abandoned open dumping area can now be reused for the new development after the long-term settlement are predicted and some of the precaution measures has been taken as a safety measures.
\end{abstract}

Keyword: Empirical model; Long-term settlement; Open dumping area; Prediction model 